\title{
CHITOSAN METAL COMPLEXES AND CHITOSAN- Cu ESR STUDIES
}

\author{
EDELIO TABOADA VALDÉS ${ }^{I}$, GALO CARDENAS TRIVIÑO
}

\begin{abstract}
${ }^{1}$ Escuela de Ingeniería Ambiental, Facultad de Ingeniería, Universidad Católica de Temuco, Temuco, Chile, etaboada@uct.cl Galo Cárdenas Triviño*, ${ }^{2}$ Laboratorio de Materiales Avanzados, Departamento de Polímeros Universidad de Concepción, Casilla 160-C, Concepción, Chile. (Received 1 August 2007 - Accepted 12 November 2008)
\end{abstract}

\begin{abstract}
Properties of the polymer metal complexes can be explained up to certain extent by the molecular structure of the complexes, but this area has not been well studied in the case of the chitosan metal complexes. In this work, we are proposing that chitosan is bonded through the 4 nitrogen to copper by means of square planar geometry. The polymer requires some structural modifications in order to be arranged in that geometry. Two sites in the chitin were detected, one similar to chitosan and the other in a square planar tetrahedrically distorted arrangement, with three atoms of nitrogen and one of oxygen or two atoms of nitrogen and two of oxygen. ESR studies of the copper complexes by means of chlorine and nitrate as ion counter were carried out. Nitrate exhibits one type of retention site and, on the other hand, chlorine presents two types of retention sites.
\end{abstract}

Keywords: Chitosan, metal complexes, esr, retention sites.

\section{INTRODUCTION}

Several publications on chitosan complexes have been carried out in order to trap metal ions at different $\mathrm{pH}^{1}$. Chitosan phosphate and chitosan dithiocarbamate were synthesized by Lopez de Alba ${ }^{2}$ to trap uranium (VI). Lasko ${ }^{3}$ obtained derivatives from mercaptosuccinic acid, pyridoxal hydrochloride and succinamide and a comparison with chitosan retention against $\mathrm{Cu}$ (II), Cd (II), $\mathrm{Fe}(\mathrm{II})$ and $\mathrm{Pb}$ (II) was carried out. Guibal has prepared a graft copolymer with oxo-2-glutaric acid in order to trap both uranium and vanadium ${ }^{4}$.

Among the few attempts to understand more about the structure that different metal ions produces with chitosan, it must be noted the work reported by Schlick ${ }^{5}$, in which an ESR study on the $\mathrm{Cu}$ (II) bond sites in chitin and chitosan, respectively was performed.

Other similar studies using this technique, combined with Mössbauer spectroscopy, proposed a square planar structure for $\mathrm{Cu}(\mathrm{II})$ ion and a distorted rombic array for the Fe(III) complex with chitosan ${ }^{6}$. Mössbauer spectroscopy was also used to study the interactions between decamers and chitosan polymers with different $\mathrm{Fe}$ ions, concluding that there is an important participation of two $\mathrm{NH}_{2}$ group and two $\mathrm{OH}$ from two glucosamine units. This result is in agreement with that one obtained by an X-ray study where a relation between two units of glucosamine by one metal ion salt molecule ${ }^{7}$ is proposed.

The interaction of uranyl ions with chitosan was studied by UV-vis and FTIR spectroscopy; and the participation of only one $\mathrm{NH}_{2}$ in the complex was proposed $^{8}$. Domard ${ }^{9}$ studied the copper chitosan complex by means of the circular dicroism and, in this case, the presence of the $\mathrm{OH}$ group in the complex besides the nitrogen atoms is postulated. In another work related to the interaction of $\mathrm{Cu}(\mathrm{II})$ with chitosan oligomers and the polymer dissolved using UV-vis, potenciometry and circular dicroism, the possibility to form complexes with the involvement of either one or two $\mathrm{NH}_{2}$ is described.

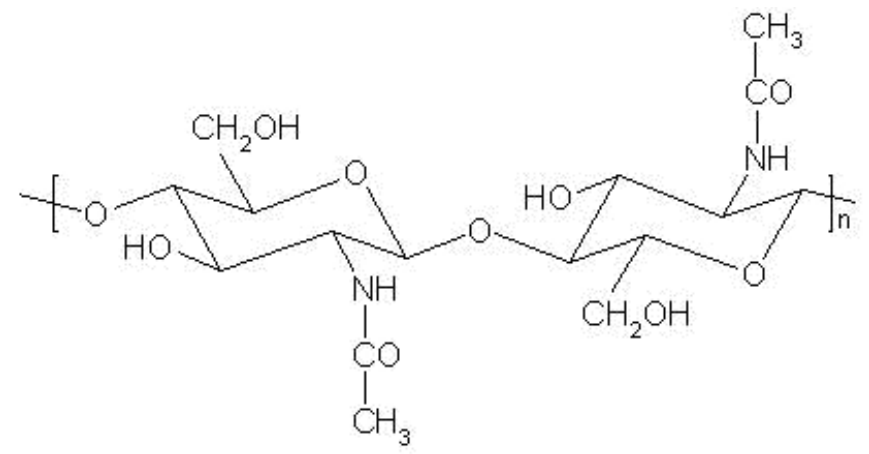

Chitin

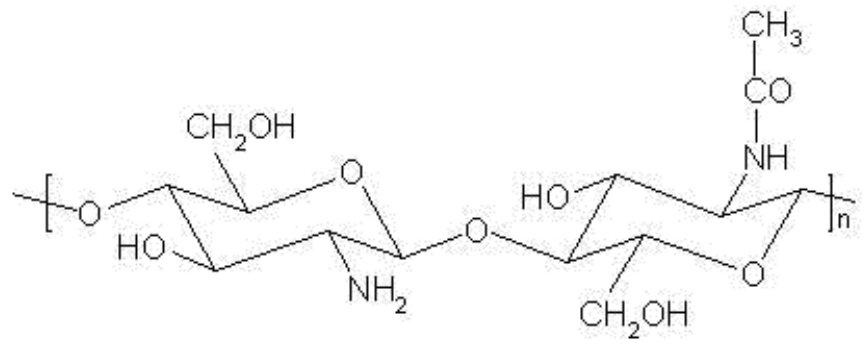

Chitosan

\section{EXPERIMENTAL PART}

In the complex nomenclature, sometimes the amount of metal present is related to the polymer mass. This concentration is calculated by a mass balance between the amount of metal in the initial solution and the metal remaining in the final solution after the contact with the polymer. This determination is carried out by atomic absorption spectroscopy. For the specific case of mercury, the detection limit is $10 \mathrm{mg} / \mathrm{L}$ and the lower concentration is yet unknown. In this case, the "a" prefix in which the starting solution was $50 \mathrm{mg} / \mathrm{L}$ and the "b" prefix when the concentration was $600 \mathrm{mg} / \mathrm{L}$ was used.

In ESR spectroscopy, the complexes studied were prepared from metallic solutions with a $2000 \mathrm{mg} / \mathrm{L}$ concentration. With this technique, the influence of parameters such as degree of deacetylation and crystallinity of the polymer in the $\mathrm{Cu}(\mathrm{II})$ complex was studied. The influence of two different ion counters $\left(\mathrm{NO}_{3}{ }^{-}\right.$and $\left.\mathrm{Cl}^{-}\right)$in the complex formation has also been studied.

Chitins crystalline index (C.I.) was determined by X-ray difractogram, by means of the method described by Struszczyk ${ }^{10}$ for cellulose and applied to chitin through the following equation.

$$
C I=\left(\frac{I_{110}-I_{2 \mathrm{~m}}}{I_{110}}\right) \cdot 100
$$

Where $I_{110}$ is the maximum intensity in the diffraction 110 and $I_{a m}$ is the intensity of the amorphous diffraction in the same unit $2 \theta=12^{\circ} 30^{\prime}$.

Chitosan crystalline index (C.I.) was determined by infrared spectroscopy from the absorbance relation $\mathrm{A}_{1382} / \mathrm{A}_{2920}{ }^{11}$.

Polymers used in this case are:

High molecular weight chitosan of $(\mathrm{Mv}=300.000 \mathrm{~g} / \mathrm{mol})$ with C.I. $=55.8 \%$ and deacetylation degree of $98 \%$ (QAPM-1).

High molecular weight chitosan with $(\mathrm{Mv}=300.000 \mathrm{~g} / \mathrm{mol})$ previously dissolved and precipitated twice in order to decrease the crystalline (C.I. $=46.26$ $\%$ ) and deacetylation the degree remains at 98\% (QAPM-2 ). 
Low molecular weight Chitosan $(\mathrm{Mv}=85.000 \mathrm{~g} / \mathrm{mol})$ with C.I. $=27.8 \%$ and deacetylation degree of of 84\% (QBPM-1).

$\alpha$ - chitin was obtained from shrimp shells, with a deacetylation degree of $16 \%$ and C.I. $=82.7 \%$.

$\beta$-chitin was obtained from squids, with a deacetylation degree of $5 \%$ and C.I. $=66.3 \%$.

Copper complexes were prepared by batch method using $100 \mathrm{mg}$ of chitosan or its derivatives and $50 \mathrm{ml}$ of copper nitrate p.a. from a $2000 \mathrm{mg} / \mathrm{L}$ solution.

\section{ESR Methodology.}

In this work, $X$ band measurements ranges in a frequency zone from 9 to $10 \mathrm{GHz}$, and in a $Q$ band, in which the microwave is around $34 \mathrm{GHz}$. A Bruker ESP380 model was used. As we expected, the band conditioned the magnetic field where the band appears. In the X-band, the signal corresponding to the free electron appears in the field between $320 \mathrm{mT}$ and $350 \mathrm{mT}$, whiles the Q band and appears over $1.2 \mathrm{~T}^{12,13}$. Besides, the spectrum analysis is analogous for the different bands.

One very peculiar characteristic of the ESR is that the spectrum is visualized in the first derivative, but the signals are detected as sensitive phases ${ }^{10}$.

The powder spectrum

Most of the spectra studied in this work were obtained from samples in which the paramagnetic can be found in any orientation, with respect to the direction of the magnetic field measurement. This occurs in vitreous samples in which the molecules are randomly oriented respect to the others, and in polycrystalline samples, in which even if a same small amount of crystal is formed in the sample, there is a great amount of them adjusted to different orientations. Powder spectrum can be obtained in all the cases and they present typical characteristics ${ }^{14}$.

\section{RESULTS AND DISCUSION}

ESR Studies of $\mathrm{Cu}$ (II) complexes.

Chitin-Cu(II) complexes

The polymorphic differences presented by chitin in the two more common forms $(\alpha$ and $\beta$ ), offers a different molecular environment for the metallic ions; each of them due to the different chain environment. Besides, the possibilities of coordination between metal ions such as $\mathrm{Cu}(\mathrm{II})$ and nitrogen can change in each case ${ }^{15,16}$.

The ESR spectra obtained by means of MPC are shown in figures 1 and 2. In all of them, a typical signal of the $\mathrm{Cu}(\mathrm{II})$ axial complexes with a group of four peaks equally spaced, corresponding to the hyperfine parallel structure, and a perpendicular one can be observed. From this signal, $\mathrm{Cu}$ (II) center can be obtained besides the main parallel value of the hyperfine tensor. These parameters are summarized in table I.

In a few samples, another wide signal appears to be related to metallic impurities. In order to corroborate this statement, an ESR of the chitins without metal was measured and, as a matter of fact, they exhibit the presence of the same band found in the chitin-metal spectrum. The signal is quite wide and probably due to the presence of iron ions, mostly from the chitin. The high intensity of this band suggests that in the chitin, there is a greater amount of this impurity, rather than in the $\mathrm{Cu}(\mathrm{II})$ ion.
Table I: Values for the Hamiltonian spin parameters in the complex formed by the $\alpha$ and $\beta$-chitin with $\mathrm{Cu}\left(\mathrm{NO}_{3}\right)_{2}$ and $\mathrm{CuCl}_{2}$.

\begin{tabular}{|c|c|c|c|c|}
\hline Copper Complex & $\begin{array}{l}\text { Frequence } \\
\text { (MHz) }\end{array}$ & $\mathrm{g}_{\mathrm{II}} \pm \Delta \mathrm{g}_{\mathrm{II}}$ & $\begin{array}{l}\mathrm{A}_{\mathrm{II}} \pm \Delta \mathrm{A}_{\mathrm{II}} \\
\quad(\mathrm{MHz})\end{array}$ & $\mathrm{g}_{\perp} \pm \Delta \mathrm{g}_{\perp}$ \\
\hline $\begin{array}{l}\text { Chitin } \beta-\mathrm{Cu}\left(\mathrm{NO}_{3}\right)_{2}^{-} \\
\mathrm{X} \text { band }\end{array}$ & 9831,396 & $2,33 \pm 0,01$ & $368 \pm 46$ & $2,07 \pm 0.01$ \\
\hline $\begin{array}{l}\text { Chitin } \alpha-\mathrm{Cu}\left(\mathrm{NO}_{3}\right)_{2}^{-} \\
\mathrm{X} \text { band }\end{array}$ & 9831,161 & $2,32 \pm 0,01$ & $454 \pm 46$ & $2,07 \pm 0.01$ \\
\hline Chitin $\beta-\mathrm{CuCl}_{2}-\mathrm{X}$ band & 9831,598 & $2,32 \pm 0,01$ & $418 \pm 46$ & $2,07 \pm 0.01$ \\
\hline Chitin $\alpha-\mathrm{CuCl}_{2}-\mathrm{X}$ band & 9831,237 & $2,32 \pm 0,01$ & $439 \pm 46$ & $2,07 \pm 0.01$ \\
\hline $\begin{array}{l}\text { Chitin } \beta-\mathrm{Cu}\left(\mathrm{NO}_{3}\right)_{2}^{-} \\
\text {Q band }\end{array}$ & 34000 & $2,33 \pm 0,01$ & $480 \pm 46$ & $2,06 \pm 0,01$ \\
\hline $\begin{array}{l}\text { Chitin } \alpha-\mathrm{Cu}\left(\mathrm{NO}_{3}\right)_{2}^{-} \\
\text {Q band }\end{array}$ & 34000 & $2,32 \pm 0,01$ & $450 \pm 46$ & $2,07 \pm 0,01$ \\
\hline $\begin{array}{l}\text { Chitin } \beta-\mathrm{CuCl}_{2}^{-} \\
\text {Q band }\end{array}$ & 34000 & $2,32 \pm 0,01$ & $558 \pm 46$ & $2,07 \pm 0,01$ \\
\hline $\begin{array}{l}\text { Chitin } \alpha-\mathrm{CuCl}_{2}{ }^{-} \\
\text {Q band }\end{array}$ & 34000 & $2,32 \pm 0,01$ & $658 \pm 46$ & $2,07 \pm 0,01$ \\
\hline
\end{tabular}

The signal corresponding to copper which values are in table I, exhibit a great apparent intensity in the $\alpha$-chitin rather than in the $\beta$-chitin. This can be due to the fact that the $\alpha$-conformation retains an amount of copper greater than the $\beta$-conformation. Besides, the $\alpha$-complex is well defined and remains stable even if the $\mathrm{NO}_{3}$ - ion counter changes by the $\mathrm{Cl}^{-}$presence. In the $\beta$-chitin, it does not occur in the same way, since the signal changes the form when the ion counter changes, showing a better defined signal corresponding to copper, when $\mathrm{Cl}^{-}$was used. This observation suggests the participation of the ion counter in the complex formation.

The above analyses suggest that the complexes formed in each case are different, which is in agreement with the differences existed in the main arrangements. It is known that $\alpha$-chitin can have a greater amount of $\mathrm{OH}$ groups closed one to another, because of the anti parallel chain arrangement. The interaction of these groups produces more rigidity than the $\beta$-chitin, where the arrangement is parallel and besides the $\mathrm{OH}$ is not enabled to interact.

This vicinity of the $\mathrm{OH}$ groups and the oxygen of the acetamide group in the $\alpha$-chitin, proposes a possible coordination center for the metallic ions. It is expected that $\mathrm{Cu}$ (II) complexes are formed by the oxygen ligand of several chains. These complexes exhibit a low symmetry, because the metallic ions must get coordinated to the available sites, which are not abundant and showed great rigidity. The high values of $g_{\text {II }}$ are according with these observations.

In a previous work ${ }^{17}$, the presence of two types of metal coordination sites it was proposed and, in one of them, the nitrogen participate in the complex formation. Due to the great steric hinderance of the acetamide group, this is not able to get coordinated with the metal ion and the active site is related with the nitrogen, of the free amine group of the chitin. This is another way to find the deacetylation degree of the chitin related with the coordination site in the ESR spectrum. This type of site can appears in the chitosan and it has been mentioned above.

The $\alpha$-chitin used, exhibit a deacetylation degree of $16 \%$ and the $\beta$-chitin only $5 \%$. As consequence, the $\alpha$-chitin presents more free amine groups. However, for both chitin studied, the ESR presented only one coordination site. That site is different to that already mentioned and appears in the chitosan spectra. Then, it can be assumed that our observed coordination site can only be related to the oxygen atoms. The amine involved can be inhibited by the impurities presence. 


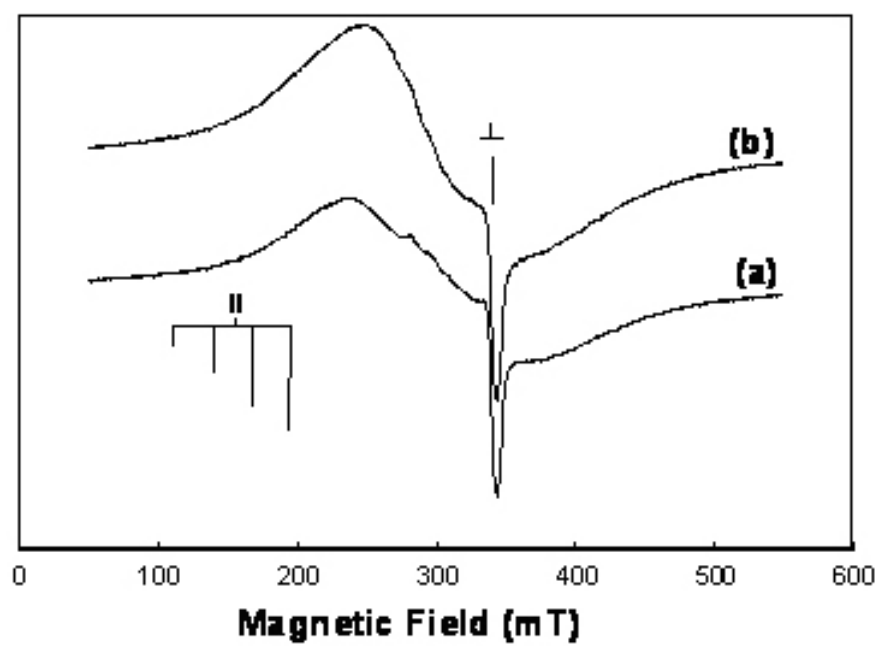

Figure 1.- ESR spectrum in $\mathrm{X}$ band of the $\alpha$-chitin complexes with (a) $\mathrm{Cu}\left(\mathrm{NO}_{3}\right)_{2}$ and (b) $\mathrm{CuCl}_{2}$.

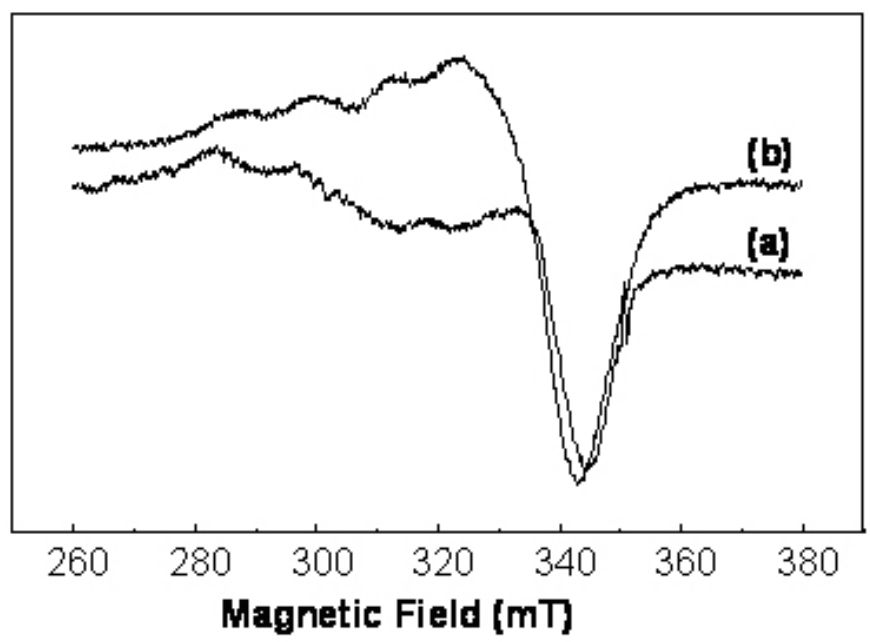

Figure 2.- ESR spectrum in $\mathrm{X}$ band of the $\beta$-chitin complexes with (a) $\mathrm{Cu}\left(\mathrm{NO}_{3}\right)_{2}$ and (b) $\mathrm{CuCl}_{2}$.

\section{Chitosan complexes - $\mathrm{Cu}(\mathrm{II})$}

The spectrum of the chitosan- $\mathrm{Cu}$ (II) complex, from the nitrate salt, are represented in the figure 3 . The parameters that described the signal (main values of and A, table I) are different to the chitin samples.

The $\mathrm{X}$ band spectrum in the samples with chloride (figure 4), shows a similar signal to the one of the nitrate, of low intensity with hyperfine structure and other more intense signal, without hyperfine structure, centered around $\mathrm{g}=2.1$. When the spectrum is measured in Q band (figure 5), the apparent narrowing allows to solve this signal into another that possesses the three characteristics of a $S=1 / 2$ species with an orthorombic gyromagnetic tensor and without a solved hyperfine structure. This signal corresponds to a $\mathrm{Cu}$ (II) center which hyperfine structure has been averaged to zero and with main values of the $g$ tensor such as those ones summarized in table II.

The summarized values in table II and III, are very similar when the same ion counter is used independently of the chitosan. Furthermore, it can be assumed that $\mathrm{Cu}(\mathrm{II})$ ion is preferentially coordinated in such a way independently of the molecular weight and crystalline degree of the chitosan. Since this coordination site is different to that observed in the chitin and chitosans, much more metal is retained, it can be expected that nitrogen, from the amine groups, is involved in the complex formation.

To determine the crystalline effect in the metal retention, we compared the chitosan QAPM-1 and QAPM-2, with the same deacetylation degree, the same molecular weight and obtained from the same source, but with different crystalline degree.

In the ESR spectrum presented in figures 3 and 4, it is observed that chitosan with lower crystalline degree (QAPM-2) produces wider bands and with greater intensity than the chitosan more crystalline (QAPM-1), for both ion counters. These characteristics of the bands can be correlated to a greater amount of metal retention considering that all the other conditions remain constant. From this analysis it can be concluded that metal ions are trapped in the amorphous zone of the polymer.

It has been previously proposed that deacetylation degree possesses a great influence on the amount of metal trapped by the polymer and it can be assumed when the deacetylation degree increase, the amount of metal trapped increases. This statement is corroborated from the ESR spectrum obtained in this work, since the more deacetylated (QAPM-1 and QAPM-2, DD $=98 \%$ ), presents wider bands and with greater intensity than chitosan lower deacetylated (QBPM-1, $\mathrm{DD}=84 \%$ ). QAPM-1, presents higher crystalline index than QBPM-1 and traps a higher amount of metal, due to their higher DD.

Table II: Values of the Hamiltonian spin parameters in the chitosan complexes with $\mathrm{Cu}\left(\mathrm{NO}_{3}\right)_{2}$.

\begin{tabular}{|c|c|c|c|c|}
\hline Copper complexes & $\begin{array}{l}\text { Frequence } \\
(\mathrm{MHz})\end{array}$ & $\mathrm{g}_{\mathrm{II}} \pm \Delta \mathrm{g}_{\mathrm{II}}$ & $\begin{array}{l}\mathrm{A}_{\text {III }} \pm \Delta \mathrm{A}_{\text {II }} \\
(\mathrm{MHz})\end{array}$ & $\mathrm{g}_{\perp} \pm \Delta \mathrm{g}_{\perp}$ \\
\hline $\begin{array}{c}\left.\text { QAPM-1 Cu(NO})_{3}\right)_{2}, \\
\text { X band }\end{array}$ & 9831,076 & $\begin{array}{c}2,264 \pm \\
0,005\end{array}$ & $503 \pm 22$ & $\begin{array}{c}2,091 \pm \\
0,006\end{array}$ \\
\hline $\begin{array}{l}\text { QAPM- } 2, \mathrm{Cu}\left(\mathrm{NO}_{3}\right)_{2}, \\
\quad \mathrm{X} \text { band }\end{array}$ & 9831,467 & $\begin{array}{c}2,261 \pm \\
0,005\end{array}$ & $510 \pm 22$ & $\begin{array}{c}2,089 \pm \\
0,006\end{array}$ \\
\hline $\begin{array}{c}\text { QBPM-1, } \mathrm{Cu}\left(\mathrm{NO}_{3}\right)_{2}, \\
\text { X band }\end{array}$ & 9831,539 & $\begin{array}{c}2,261 \pm \\
0,005\end{array}$ & $509 \pm 22$ & $\begin{array}{c}2,091 \pm \\
0,006\end{array}$ \\
\hline $\begin{array}{c}\text { QAPM-1, } \mathrm{Cu}\left(\mathrm{NO}_{3}\right)_{2}, \mathrm{Q} \\
\text { band }\end{array}$ & 34000 & $2,26 \pm 0,01$ & $491 \pm 40$ & $\begin{array}{c}2,07 \pm \\
0,01\end{array}$ \\
\hline $\begin{array}{l}\text { QAPM-2, } \mathrm{Cu}\left(\mathrm{NO}_{3}\right)_{2}, \\
\text { Q band }\end{array}$ & 34000 & $2,26 \pm 0,01$ & $491 \pm 40$ & $\begin{array}{c}2,07 \pm \\
0,01\end{array}$ \\
\hline $\begin{array}{c}\text { QBPM-1, } \mathrm{Cu}\left(\mathrm{NO}_{3}\right)_{2}, \\
\text { Q band }\end{array}$ & 34000 & $2,26 \pm 0,01$ & $491 \pm 40$ & $\begin{array}{c}2,07 \pm \\
0,01\end{array}$ \\
\hline
\end{tabular}

It is very important to denote this phenomena when the salt of $\mathrm{NO}_{3}$-salt is changed by $\mathrm{Cl}^{-}$. With the $\mathrm{NO}_{3}{ }_{3}^{-}$one site type of retention is observed, on the other hand, in the $\mathrm{Cl}^{-}$two types of sites can be observed. One of these sites corresponds to the one observed in the $\mathrm{NO}_{3}$ - spectrum but the other is completely different and besides, with the preference for the coordination of the metal ion since their signal is more intense ${ }^{18,19}$.

Table III: Values of the Hamiltonian spin parameters in the chitosan complexes formed with $\mathrm{CuCl}_{2}$.

\begin{tabular}{|c|c|c|c|c|}
\hline Copper complexes & $\begin{array}{c}\text { Frequence } \\
(\mathrm{MHz})\end{array}$ & $\mathrm{gx} \pm \Delta \mathrm{gx}$ & $\mathrm{gy} \pm \Delta \mathrm{gy}$ & $\mathrm{gz} \pm \Delta \mathrm{gz}$ \\
\hline $\begin{array}{c}\text { QAPM-1 CuCl} \\
\mathrm{X} \text { band }\end{array}$ & 9830,95 & $2,18 \pm 0,01$ & - & $2,07 \pm 0,01$ \\
\hline $\begin{array}{c}\text { QAPM-2, CuCl} \\
\mathrm{X} \text { band }\end{array}$ & 9830,832 & $2,19 \pm 0,01$ & - & $2,04 \pm 0,01$ \\
\hline $\begin{array}{c}\text { QBPM-1, CuCl} \\
\mathrm{X} \text { band }\end{array}$ & 9830,523 & $2,18 \pm 0,01$ & - & $2,08 \pm 0,01$ \\
\hline $\begin{array}{c}\text { QAPM-1, } \mathrm{CuCl}_{2}, \\
\mathrm{Q} \text { band }\end{array}$ & 34000 & $\begin{array}{c}2,17 \pm \\
0,01\end{array}$ & $2,11 \pm 0,01$ & $2,05 \pm 0,01$ \\
\hline $\begin{array}{c}\text { QAPM-2, } \mathrm{CuCl}_{2}, \mathrm{Q} \\
\text { band }\end{array}$ & 34000 & $\begin{array}{c}2,18 \pm \\
0,01\end{array}$ & $2,11 \pm 0,01$ & $2,05 \pm 0,01$ \\
\hline $\begin{array}{c}\text { QBPM }-1, \mathrm{CuCl}_{2}, \\
\mathrm{Q} \text { band }\end{array}$ & 34000 & $\begin{array}{c}2,17 \pm \\
0,01\end{array}$ & $2,11 \pm 0,01$ & $2,05 \pm 0,01$ \\
\hline
\end{tabular}

This new site, where the chlorine must be included inside the complex, collapses the hyperfine structure of copper and the axial system is converted into 
a orthorhombic system where both main values of the tensor are very similar. This is observed more clear in the $\mathrm{Q}$ band experiment (figure 5).

This phenomenom occurs when the system is formed by copper clusters where the ions are coupled by a long range of magnetic exchanges. In order to achieve this, the copper center must be formed by a short distance complex

between them. The exchange produces a partial average of the $g_{\text {ef. }}$ tensor main value.

This clusters would be relatively long or very long chains (more than 8 $\mathrm{Cu}(\mathrm{II})$ ) with common ligands, always in the same form and when the $\mathrm{Cu}(\mathrm{II})$ keeps the structure axis.

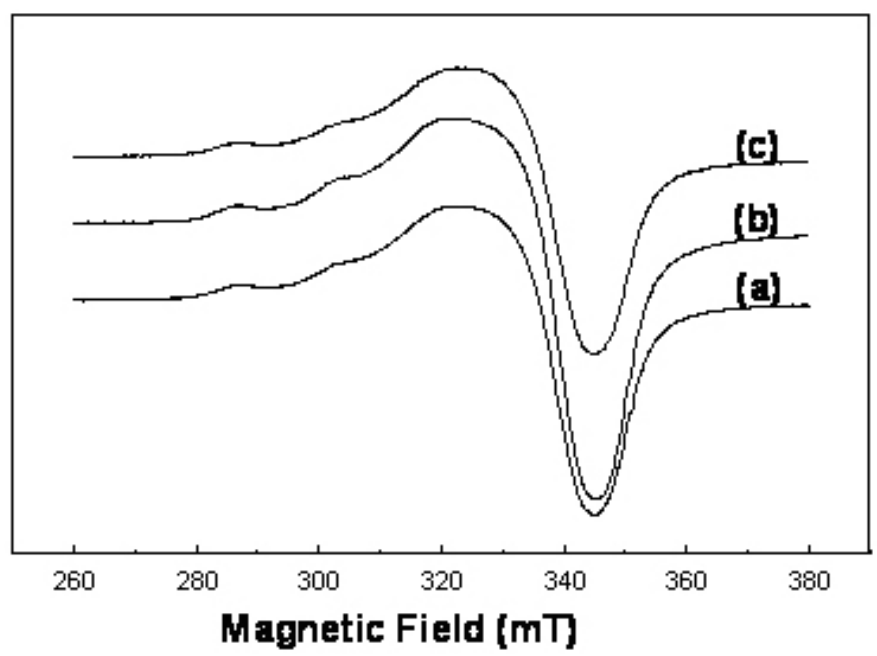

Figure 3. ESR spectrum in the $X$ band of the complexes from different chitosan types with $\mathrm{Cu}\left(\mathrm{NO}_{3}\right)_{2}$ : (a) QAPM-1, (b) QAPM-2, (c) QBPM-1.

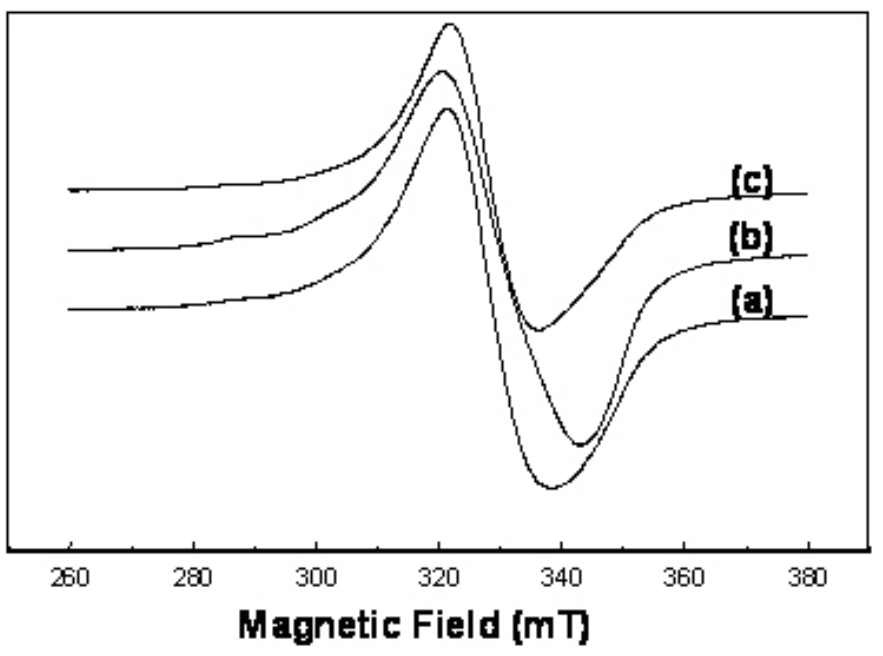

Figure 4. ESR spectrum in the $\mathrm{X}$ band of the complexes from different chitosan types with $\mathrm{CuCl}_{2}$ : (a) QAPM-1, (b) QAPM-2, (c) QBPM-1.

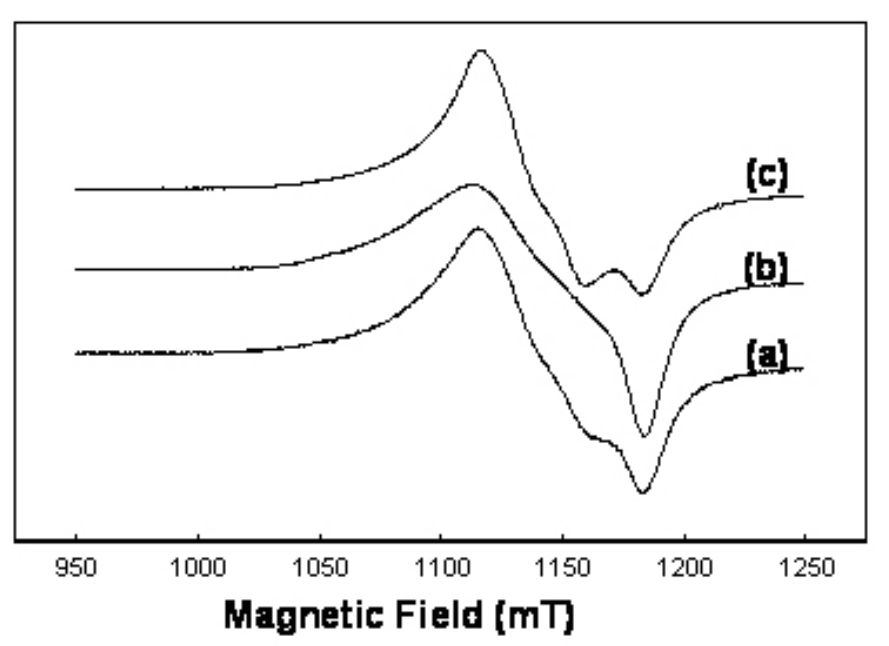

Figure 5. ESR spectrum in the $\mathrm{Q}$ band of the complexes from different chitosan types with $\mathrm{CuCl}_{2}$ : (a) QAPM-1, (b) QAPM-2, (c) QBPM-1.

\section{CONCLUSIONS}

By using ESR, it is possible to characterize copper complexes with $\alpha$-chitin and $\beta$-chitin, which are different in each case due to the difference in the existence of the chain arrangement. $\alpha$-chitin retains an amount of copper greater than $\beta$-chitin. Besides, the complex with the $\alpha$-chitin is well defined and remains, even when the $\mathrm{NO}_{3}^{-}$ion counter has been changed by $\mathrm{Cl}^{-}$. In the $\beta$-chitin, the centers are different depending upon the ion counter.

The ESR allows to characterize the copper complex with chitosan with different characteristics, such as crystalline and degree of deacetylation and their influence in the complex formation is determined. The crystalline degree affects the capacity of chitosan to retain copper and, according to the experiments, the copper is trapped in a great amount when the polymer exhibits a lower crystalline index. The deacetylation degree also affects the amount of metal retention. A lower amount of acetyl groups increases the retention capacity. The linear copper clusters formation was also detected when $\mathrm{Cl}^{-}$was used as ion counter. Finally, the symmetry of the metallic center depends on the original ion counter employed.

\section{ACKNOWLEDGEMENTS}

The authors would like to thank the financial support from FONDEF GRANT \# D04I-1286 and Dirección de Investigación, Universidad de Concepción.

\section{REFERENCES}

1.- (a) Muzzarelli R.A.A., Zattoni A. Int. J. Biol. Macromol, 8, Junio, 137, (1986), (1b) Muzzarelli R. A.A., Rocchetti R., Stanic V., Weckx M.: Chitin Handbook. Ed. Riccardo A.A. Muzzarelli, Martin G. Peter, Atec, Grottammare, Italy, 109, (1997), (1b) Muzzarelli R.A.A., Zattoni A. Int. J. Biol. Macromol, 8, Junio, 137, (1986, (1c) Muzzarelli R.A.A., Rocchetti R. J. of Chromatography, 96, 115, (1974).

2.- Lopez de Alba P. L., Pacheco M. A., Urbina B., Alvarado C. Bol. Soc Chil. Quim.,32, 81, (1987).

3.- Lasko C. L., Pesic B. M, Oliver D. J.: J. Appl. Polym. Sci., 48, 1565, (1993).

4.- a) Guibal E., Saucedo I., Jansson-Charrier M., Delandhe B., Le Cloirec P. Wat. Sci. Tech., 30, 183, (1994), (b) Guibal E., Vincent T., Navarro R.: J. Appl. Polym. Sci., 75, 119, (2000).

5.- Schlick Sh. Macromolecules. 19, 192, (1986).

6.- Chiessi E., Paradossi G., Venanzi M, Pispisa B. Int. J. Biol. Macromol,15, 145, (1993).

7.- Ogawa K., Oka K.: Chem. Mater., 5, 726, (1993). 
8.- Piron E., Domard A. Int. J. Biol. Macromol. 22, 33, (1998).

9.- Domard A.: Int. J. Biol. Macromol. 9, 333, (1987).

10.- Struszczyk H.: J. Appl. Polym. Sci. 33, 177, (1987).

11.- Harish Prashanth K.V., Kittur F. F., Tharanathan R. N.: Carbohydrate Polymers, 50, 27, (2002).

12.- Wertz J. E., Bolton J. R.: Electron Spin Resonance. Elementary Theory and Practical Applications. McGraw-Hill, New York, USA (1972).

13.- Chang R.: Principios Básicos de Espectroscopia. Editorial AC, Madrid, España (1977)

14.- Martínez J. I.: Tesis Doctoral. Facultad de Ciencias. Universidad de Zaragoza (1994)
15.- Muzzarelli Ricardo. A. A.: Natural Chelating Polymers, Pergamon Press Ltd., Hungary, 96-103 (1973).

16.- Muzzarelli Ricardo. A. A.: Chitin, Pergamon Press Ltd., Great Britain, 8993 (1977).

17.- Kyoon No H., Meyers S. P.: Chitin Handbook. Ed. Riccardo A.A. Muzzarelli, Martin G. Peter, Atec, Grottammare, Italy, 475-489, (1997).

18.- Taboada E., Cabrera G. ,Cárdenas G.: J. Chil. Chem. Soc. 48, 07 (2003).

19.- Cárdenas G., Parra O., Taboada E.: Int. J. Biol. Macromol. 28, 167, (2001). 